\title{
O DIREITO FUNDAMENTAL À SOLIDARIEDADE: A APLICAÇÃO DO INSTITUTO NO DIREITO CIVIL
}

THE FUNDAMENTAL RIGHT TO SOLIDARITY: APPLICATION OF THE INSTITUTE IN CIVIL $L A W$

EL DERECHO FUNDAMENTAL A LA SOLIDARIDAD: LA APLICACIÓN DEL INSTITUTO EN EL DERECHO CIVIL

Jorge Renato dos Reis ${ }^{1}$

Letícia Regina Konrad²

1 Doutor pela Università Degli Studi di Salerno, Itália. Doutor em Direito pela UNISINOS. Mestre em Desenvolvimento Regional pela UNISC. Especialista em Direito Privado. Professor e pesquisador do Programa de Pós-Graduação em Direito - Mestrado e Doutorado da Universidade de Santa Cruz do Sul. Autor de diversos artigos em revistas jurídicas no Brasil, na Espanha e na Itália. Membro do Conselho Editorial de diversas revistas jurídicas no Brasil. Líder e pesquisador-membro do grupo de pesquisa Constitucionalismo Contemporâneo: Intersecções Jurídicas entre o Público e o Privado, do Mestrado e Doutorado da UNISC.

2 Mestranda em Direitos Sociais e Políticas Públicas na Universidade de Santa Cruz do Sul UNISC, linha de pesquisa Constitucionalismo Contemporâneo e Bolsista CAPES. Integrante do grupo de Pesquisa Direitos Humanos coordenado pelo Prof. Pós Dr. Clóvis Gorczevski. Bacharel em Direito. Especialista em Direito Civil com ênfase em família e sucessões. Advogada. Mediadora Familiar. E-mail: leticiakonrad@gmail.com. 
Resumo: A solidariedade constitui-se como objetivo fundamental do Estado Democrático de Direito. Nesse sentido, pretende-se dialogar sobre a aplicabilidade do instituto frente às relações privadas, de modo a contemplar a seara contratual, ainda incipiente entre os intérpretes constitucionais. Para tanto, contextualizar-se-á a constitucionalização do direito civil a partir de uma breve abordagem entre os direitos humanos e os direitos fundamentais, enfatizando o Constitucionalismo Contemporâneo. Após, perquirirse-á compreender a (in)eficácia dos direitos fundamentais no direito civil, para que finalmente seja possível a compreensão da solidariedade como um direito fundamental, de aplicação imediata nas relações entre particulares. Para tanto, utiliza-se o método de abordagem hipotético-dedutivo com análise bibliográfica.

Palavras-chave: Solidariedade. Direitos fundamentais. Constitucionalização do Direito Civil. Relações Privadas.

Abstract: Solidarity is a fundamental objective of the democratic state. In this sense, we intend to talk about the applicability of the institute to private relations, in order to reflect on the still incipient contractual area between the constitutional interpreters. For this, it contextualizes the constitutionalization of civil law, based on a brief approach between human rights and fundamental rights, emphasizing the Contemporary Constitutionalism. It seeks to understand the (in)efficacy of fundamental rights in civil law, in order to make it possible to understand solidarity as a fundamental right, immediately applicable in relations between private individuals. We use a hypothetical-deductive approach, with a literature review.

Keywords: Solidarity. Fundamental Rights. Constitutionalization of Civil Law. Private Relationships.

Resumen: La solidaridad constituye un objetivo fundamental del Estado Democrático de Derecho. En ese sentido, se 
pretende dialogar sobre la aplicabilidad del instituto frente a las relaciones privadas, de modo que se contemple el campo contractual, todavía incipiente entre los intérpretes constitucionales. Para ello se contextualizará la constitucionalización del derecho civil a partir de un breve abordaje entre los derechos humanos y los derechos fundamentales, enfatizando el Constitucionalismo Contemporáneo. A continuación se procurará comprender la (in)eficacia de los derechos fundamentales en el derecho civil, para que finalmente sea posible la comprensión de la solidaridad como un derecho fundamental, de aplicación inmediata en las relaciones entre particulares. Para ello se utiliza el método de abordaje hipotético deductivo con análisis bibliográfico.

Palabras clave: Solidaridad. Derechos Fundamentales. Constitucionalización del Derecho Civil. Relaciones Privadas.

\section{INTRODUÇÃO}

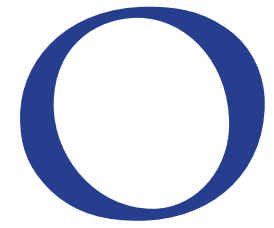

princípio da solidariedade é amplamente estudado e consolidado em alguns ramos do direito tributário e previdenciário, sendo conhecido e percebido constantemente nas decisões judiciais dessas searas. Entretanto, no presente trabalho, pretende-se tratar a solidariedade sob um enfoque não tão conhecido, no caso, o do direito civil, mais especificamente voltando-se para a seara contratual.

Sabe-se que constituem objetivos fundamentais da República Federativa do Brasil a construção de uma sociedade livre, justa e solidária (art. $3^{\circ}$, Constituição Federal ${ }^{3}$ ). Entretanto, a aplicabilidade da solidariedade ainda é um tanto quanto

3 Sarmento destaca que a Constituição expressa a solidariedade como um princípio jurídico que apresenta eficácia imediata, irradiando-se em todo o sistema jurídico: "Assim, é possível afirmar que quando a Constituição estabelece como um dos objetivos fundamentais da República brasileira "construir uma sociedade justa, livre e solidária", ela não está apenas enunciando uma diretriz política desvestida de qualquer eficácia normativa. Pelo contrário, ela expressa um princípio jurídico, que, apesar de sua abertura e indeterminação semântica, é dotado de algum grau de eficácia imediata e que pode atuar, no mínimo, como vetor 
incipiente por parte dos intérpretes constitucionais frente às relações entre particulares. Nesse sentido, pretende-se dialogar com a solidariedade na seara contratual e a sua aplicabilidade nas relações privadas.

Primeiramente, far-se-á uma abordagem dos direitos humanos aos direitos fundamentais para possibilitar o entendimento da iminente constitucionalização do direito civil e sua importância no constitucionalismo contemporâneo. Após, buscar-se-á evidenciar a questão da (in)eficácia dos direitos fundamentais no direito civil, para então, finalmente, possibilitar uma maior compreensão da solidariedade como um instrumento de direito civil. Assim, a problemática primordial consiste na aplicação do direito fundamental à solidariedade frente às relações privadas, tema ainda muito embrionário e, portanto, merecedor de uma reflexão.

Destaca-se que o estudo tem uma natureza bibliográfica, embasado na documentação indireta. O seu método de abordagem é o hipotético-dedutivo, fundamentado no estudo de doutrinadores da temática.

\section{DOS DIREITOS HUMANOS AOS DIREITOS FUNDAMENTAIS: A CONSTITUCIONALIZAÇÃO DO DIREITO CIVIL}

A percepção dos termos "direitos humanos" e "direitos fundamentais" como sinônimos ${ }^{4}$ é uma confusão constante, entretanto, a doutrina esclarece ser a expressão "direitos fundamentais" gênero do termo "direitos humanos". A expressão "direitos fundamentais" encontra-se relacionada aos "direitos humanos" previstos nas constituições nacionais, enquanto que o termo "direitos humanos" implica ser os direitos do ser humano previstos em tratados internacionais, ainda que estejam positivados na constituição de determinados países, apresentando

interpretativo da ordem jurídica como um todo" (SARMENTO, 2004, p. 295). Entretanto, no presente trabalho a perspectiva da solidariedade é voltada para a sua aplicação no direito civil, sendo a mesma percebida para tanto como um direito fundamental, que será explanado ao longo do artigo.

4 Pérez Luño (2005, p. 44) evidencia que os direitos humanos e os direitos fundamentais são utilizados muitas vezes como sinônimos. Realça que a doutrina tem enfatizado que direitos fundamentais designam os direitos positivados internamente e direitos humanos são os direitos naturais positivados nas declarações e convenções internacionais, assim como as exigências básicas relacionadas com a dignidade, liberdade e igualdade da pessoa que não tem alcançado um estatuto jurídico positivo. 
caráter supranacional ${ }^{5}$.

O termo direitos humanos ${ }^{6}$ é expresso por várias nomenclaturas ${ }^{7}$ : direitos naturais, direitos morais, direitos do homem, direitos do homem e do cidadão, direitos individuais, direitos do povo trabalhador, direitos fundamentais, direitos públicos subjetivos, liberdades públicas e a confusão terminológica é amplamente visualizada inclusive na Constituição Federal brasileira: direitos humanos (art. $\left.4^{\circ}, \mathrm{II}\right)$, direitos e liberdades constitucionais (art. 50, LXXI), direitos e garantias fundamentais (art. $5^{\circ}, \S 1^{\circ}$ ), direitos e garantias individuais (art. 60, $4^{\circ}, \mathrm{IV}$ ).

Ante a problemática da delimitação conceitual e da definição terminológica dos direitos humanos ${ }^{8}$, Pérez Luño ${ }^{9}$ esclarece que, conforme o momento histórico,

5 REIS, Jorge Renato dos. A vinculação dos particulares aos direitos fundamentais nas relações interprivadas: breves considerações. In: Direitos sociais e políticas públicas: desafios contemporâneos. Tomo 5. Santa Cruz do Sul: EDUNISC, 2005.

6 Para Streck e Morais (2003, p. 139) direitos humanos são um "[...] conjunto de valores históricos básicos e fundamentais, que dizem respeito à vida digna jurídico-político-psíquico-física e efetiva dos seres e de seu habitat, tanto aqueles do presente quanto daqueles do porvir, surgem sempre como condição fundante da vida, impondo aos agentes políticojurídico-sociais a tarefa de agirem no sentido de permitir que a todos seja consignada a possibilidade de usufruí-los em benefício próprio e comum ao mesmo tempo".

7 Cada denominação surge com determinado contexto histórico político, irradiado pela carga ideológica do tempo. As mais conhecidas são: (1) direitos naturais - sua matriz filosófica é utilizada amplamente em teorias jusnaturalistas, desde o renascimento, tendo sua divulgação ligada ao período do racionalismo, quando o direito natural era entendido como um conjunto de direitos inatos ao homem e anteriores ao Estado. (2) direitos do homem - denominação mais antiga. Amplamente conhecida por ser um termo redundante, de caráter individualista, tendenciando um sentido discricionário e excludente da mulher. (3) direitos do homem e do cidadão - termo cuja origem encontra-se no contrato social, entendido como os direitos do indivíduo frente o Estado. Expressão consolidada na Revolução Francesa e proclamações seguintes. (4) direitos individuais - o poder do Estado totalitário e absolutista deve ser limitado pelos direitos individuais do homem, portanto trata-se de uma expressão própria do liberalismo como forma de contraponto ao Estado. (5) liberdades públicas - nomenclatura criada pelo Estado Liberal de Direito, em substituição ao termo direitos naturais por liberdades fundamentais. (6) direitos da pessoa humana - denominação própria de escritores católicos, para evidenciar a qualidade de pessoa do ser humano. (7) direitos do povo trabalhador - expressão utilizada pelos revolucionários bolcheviques. Com a Revolução Russa em 1917, ocorre a publicação da Declaração dos Direitos do Povo Trabalhador e Explorado, a qual enuncia princípios voltados ao povo trabalhador explorado pela burguesia. (8) direitos fundamentais do homem - tal expressão aparece durante a Revolução Francesa e se difunde realmente a partir do constitucionalismo alemão. Atualmente é muito utilizada pela doutrina (GORCZEVSKI, 2009, p. 22-23).

8 A expressão "direitos humanos" ou "direitos do homem" no século XVIII apresentou-se como um critério inspirador, servindo de medida para todas as instituições jurídico-políticas, tendo grande importância na idealização de doutrinas e práticas políticas principalmente a partir do pós-guerra naquele mesmo século. Ainda há de se advertir a importância primordial que os direitos humanos ocuparam no tratamento dos argumentos mais variados de caráter social, político e jurídico (PÉREZ-LUÑO, 2005, p. 24).

9 PÉREZ-LUÑO, Antonio Enrique. Derechos humanos, Estado de Derecho y Constituci- 
tais direitos receberam "significados de uso" (ou nomenclaturas) específicos, provenientes de uma linguagem comum de valores, concepções e realidades sociais, que por sua vez influenciaram no processo de positivação dos direitos humanos. Assim, o autor delimita o alcance de cada um desses "significados de uso", tais como: direitos fundamentais, aqueles direitos humanos ${ }^{10}$ positivados nas Constituições de cada Estado; direitos subjetivos, aqueles constituídos dos bens incorpóreos, que podem ser cedidos à vontade/autodeterminação de um indivíduo, estando amplamente relacionado à autonomia da vontade; direitos públicos subjetivos, relacionados à autolimitação estatal em benefício de determinadas esferas de interesse privado; direitos individuais, entendidos como direitos civis e políticos reconhecidos a cada indivíduo e liberdades públicas, pautados aos poderes de autodeterminação reconhecidos pelo direito positivo.

A história dos direitos humanos ${ }^{11}$ pode ser dividida em três grandes épocas: $\left.1^{a}\right)$ do pré-campo histórico do pensamento humano que vai desde a antiguidade até o iluminismo; $2^{a}$ ) dos direitos humanos garantidos exclusivamente pelo Estado que vai desde o iluminismo até o primeiro terço do século $X X ; 3^{a}$ ) da proteção internacional dos direitos humanos, que tem seu começo em 1815, marcado pela proibição do tráfico negreiro africano no Congresso de Viena e, em 1945, com a fundação da $\mathrm{ONU}^{12}$. Ainda, uma $4^{\mathrm{a}}$ época pode estar em formação: a pluralização intelectual dos direitos humanos ${ }^{13} \cdot 14$

ón. 9. ed. Madrid: Tecnos, 2005.

10 Para Pérez Luño (2005, p. 48), os direitos humanos aparecem como um "conjunto de faculdades e instituições que, em cada momento histórico, concretiza as exigências da dignidade, da liberdade, da igualdade humana", as quais devem ser reconhecidas positivamente pelo ordenamento jurídico nacional e internacional.

11 Os direitos humanos não são apenas aqueles positivados, mas sim valores superiores que perduram ao longo do tempo e estão em constante transformação, apresentando um reconhecimento histórico (GORCZEVSKI, 2009). Eles nascem com o homem, são universais, fundamentais, inalienáveis, absolutos, exigíveis em qualquer Estado, representando condições mínimas para uma vida digna. Daí seu entendimento no sentido que são unicamente pré-estatais, ou naturais, não dependendo da sociedade para ter efetividade e cabendo ao Estado a sua proteção.

12 A ONU constrói a sua definição de direitos humanos a partir de três princípios: "a invulnerabilidade do corpo humano (p. ex., contra torturas), a invulnerabilidade do espírito humano (p. ex., contra repressão da liberdade de pensamento e de expressão da opinião) e ao mesmo tratamento, sem tomar em considerações gênero, raça, estado e nação. Esses princípios significativos fornecem a base da reivindicação de validade universal dos Direitos Humanos". (HAHN, 2010, p. 14).

13 HAHN, Paulo. Repensar os Direitos Humanos no Horizonte da Pluralização e da Interculturalidade. In: HAHN, Paulo (Org.). Nova Petrópolis: Nova Harmonia, 2010. p. 17.

14 A ideia de direitos humanos e o princípio da democracia é a "expressão mais significativa 
Para Bobbio (2004), os direitos humanos são históricos, modificáveis, suscetíveis de constante transformação e alargamento de seus horizontes, não sendo produto da natureza, mas sim da civilização humana ${ }^{15}$.

Nesse diapasão, os direitos humanos são valores superiores que existem no mundo axiológico, enquanto que os direitos fundamentais, nomenclatura do mundo jurídico, são os direitos humanos positivados, trazidos para o mundo real ${ }^{16}$.

Os direitos humanos são pervertidos no exato momento em que se tomam objeto de tratamento jurídico, pois, concebidos historicamente como um mecanismo de proteção dos cidadãos livres contra o arbítrio dos governantes [...] eles são esvaziados na medida em que é o próprio Estado que os regulamenta ${ }^{17}$.

Os direitos fundamentais nascem da positivação ${ }^{18}$ dos direitos humanos, como também aponta Canotilho:

(...) as expressões direitos dos homem e direitos fundamentais são frequentemente utilizadas como sinônimas. Segundo a sua origem e significado poderíamos distingui-las da seguinte maneira: direitos do

da normatividade política na era moderna" (HAHN, 2010, p. 14).

15 "Sabemos hoje que também os direitos ditos humanos são o produto não da natureza, mas da civilização humana; enquanto direitos históricos, eles são mutáveis, ou seja, suscetíveis de transformação e de ampliação. Basta examinar os escritos dos primeiros jusnaturalistas para ver quanto se ampliou a lista dos direitos: Hobbes conhecia apenas um deles, o direito à vida. Como todos sabem, o desenvolvimento dos direitos do homem passou por três fases: num primeiro momento, afirmaram-se os direitos de liberdade, [...] num segundo momento, foram promulgados os direitos políticos, [...] finalmente, foram proclamados os direitos sociais, que expressam o amadurecimento de novas exigências - podemos dizer de novos valores [...]". (BOBBIO, 2004, p. 32)

16 GORCZEVSKI, Clovis. Direitos humanos, educação e cidadania: conhecer, educar, praticar. Santa Cruz do Sul: Edunisc, 2009.

17 LEAL, Rogério Gesta. Direitos Humanos no Brasil: desafios à democracia. Porto Alegre: Livraria do Advogado; Santa Cruz do Sul: Edunisc, 1997. p. 154.

18 Sánchez Rubio (2010) destaca que o processo de institucionalização e reconhecimento normativo dos direitos humanos pode acarretar certo vazio de conteúdo, verificando assim a "eficácia minimalista, reduzida e insuficiente" em relação à quantidade esmagadora de abusos cometidos contra os direitos humanos diariamente, bem como tipo de garantias procedimentais que se estabelecem como remédios àqueles. A institucionalização e a normatização dos direitos humanos reduzem a efetivação apenas à sua violação, quando evidenciada uma demanda judicial. Entretanto, esclarece o autor que os direitos humanos existem antes mesmo de serem violados, compreendendo sua significação uma grandeza bem maior, dotada de muita luta social e reivindicações populares. Os direitos humanos manifestam-se nas tramas sociais a partir da dominação à libertação ou à emancipação dos sujeitos, apresentando-se em práticas sociais e ações diárias de todo e qualquer ser humano, abrangendo desse modo seu significado um conteúdo além do formal. 
homem são direitos válidos para todos os povos e em todos os tempos; direitosfundamentaissãoosdireitosdohomem,jurídico-institucionalmente garantidos e limitados espaço-temporalmente. Os direitos do homem arrancariam da própria natureza humana e daí o seu caráter inviolável, intertemporal e universal; os direitos fundamentais seriam os direitos objetivamente vigentes numa ordem jurídica concreta ${ }^{19}$.

Para Canotilho, a positivação dos direitos fundamentais significa a incorporação dos direitos naturais e inalienáveis do indivíduo na ordem jurídica positiva. Antes de positivados os direitos são mera "retórica política" e não direitos constitucionalmente protegidos sob forma de normas constitucionais, entendase, regras e princípios ${ }^{20}$.

Alexy denota que há uma relação muito tênue entre os direitos humanos e os direitos fundamentais. Os direitos humanos seriam universais, fundamentais, preferenciais, abstratos e morais. Entretanto, é justamente a moralidade que proporciona um "caráter suprapositivo", distinguindo os direitos humanos dos direitos fundamentais. Para o autor, direitos fundamentais "são direitos que foram acolhidos em uma constituição com o intuito e com a intenção de positivar os direitos do homem"21.

Direitos fundamentais são direitos públicos-subjetivos de pessoas (físicas ou jurídicas), contidos em dispositivos constitucionais e, portanto, que encerram caráter normativo supremo dentro do Estado, tendo como finalidade limitar o exercício do poder estatal em face da liberdade individual ${ }^{22}$.

Sarmento também esclarece que os direitos fundamentais não são "entidades estéreas, metafísicas, que sobrepairam o mundo real. Pelo contrário, são realidades históricas, que resultam de lutas e batalhas travadas no tempo, em prol da afirmação da dignidade humana"23. Os direitos fundamentais transformaram-se

19 CANOTILHO, José Joaquim Gomes. Direito Constitucional e a teoria da constituição. 2. ed. Coimbra: Almedina, 1998. p. 259.

20 CANOTILHO, José Joaquim Gomes. Direito Constitucional e a teoria da constituição. 2. ed. Coimbra: Almedina, 1998. p. 347.

21 ALEXY, Robert. Constitucionalismo discursivo. Tradução de Luís Afonso Heck. 2. ed. rev. Porto Alegre: Livraria do Advogado, 2008. p. 10.

22 DIMOULIS, Dimitri; MARTINS, Leonardo. Teoria geral dos direitos fundamentais. 3. ed. rev.atual. e ampl. São Paulo: Editora Revista dos Tribunais, 2011. p. 49.

23 SARMENTO, Daniel. Direitos fundamentais e relações privadas. Rio de Janeiro: Lumen Juris, 2004. p. 18. 
ao longo do tempo, tanto com relação ao seu conteúdo, quanto à titularidade, à eficácia e à efetivação ${ }^{24}$.

Para Sarlet ${ }^{25}$, direitos fundamentais ${ }^{26}$ são direitos humanos reconhecidos e positivados pelo direito constitucional positivo de um Estado, enquanto direitos humanos guardam relação com os documentos de ordem internacional, tratandose de posicionamentos jurídico-políticos responsáveis pelo reconhecimento de direitos e liberdades ao ser humano, independente de sua vinculação à determinada constituição, apresentando, portanto, um caráter supranacional ${ }^{27}$.

\section{Esclarecida a diferenciação entre os termos direitos humanos e direitos} fundamentais, deixa-seclaroquequandoseestáfalandoem direitosfundamentais ${ }^{28}$

24 SARLET, Ingo Wolfgang. A eficácia dos direitos fundamentais: uma teoria geral dos direitos fundamentais na perspectiva constitucional. 10. ed. ver. atual. e ampl. Porto Alegre: Livraria do Advogado, 2009. p. 45.

25 SARLET, Ingo Wolfgang. A eficácia dos direitos fundamentais: uma teoria geral dos direitos fundamentais na perspectiva constitucional. 10. ed. ver. atual. e ampl. Porto Alegre: Livraria do Advogado, 2009. p. 32.

26 "Direitos fundamentais são, portanto, todas aquelas posições jurídicas concernentes às pessoas, que, do ponto de vista do direito constitucional positivo, foram, por seu conteúdo e importância (fundamentalidade em sentido material), integradas ao texto da Constituição e, portanto, retiradas da esfera de disponibilidade dos poderes constituídos (fundamentalidade formal), bem como as que, por seu conteúdo e significado, possam Ihes ser equiparados, agregando-se à Constituição material, tendo, ou não, assento na Constituição formal" (SARLET, 2009, p. 85).

27 Sarlet (2003) faz uma importante diferenciação entre os termos direitos humanos e direitos fundamentais, posicionando-se no sentido de entender como correto os direitos fundamentais aqueles direitos humanos reconhecidos e positivados em um Estado, enquanto que os direitos humanos apresentam-se com uma característica bem peculiar de caráter supranacional. Ainda, evidencia a diferenciação entre termos como direitos do homem, considerados aqueles direitos naturais ainda não positivados; os direitos humanos, considerados aqueles positivados na esfera internacional; bem como os direitos fundamentais, tidos como aqueles direitos outorgados e reconhecidos pelo direito interno de cada Estado.

28 Luiz Fernando Calil de Freitas (informação verbal, 14/10/2013) esclareceu em palestra ministrada junto ao Curso de Atualização em Direitos Fundamentais, 4a edição, realizado junto à sede da Escola Superior da Advocacia em Porto Alegre/RS que existem três conceitos de direitos fundamentais: a) formal: vinculado à corrente de Luigi Ferrajoli, que se vincula às expectativas positivas (a prestação ou negativas (a não lesões) que, enquanto direitos subjetivos dizem respeito universalmente a todos os seres humanos dotados de status de cidadão ou pessoa capaz de agir; b) procedimental: vinculada à corrente de Robert Alexy, consiste na percepção dos direitos fundamentais como um feixe de posições protegidas pela norma jusfundamental com fundamento na liberdade e na igualdade; c) substancial: relacionada à corrente de Ronald Dworkin, que verifica os direitos fundamentais como direitos morais fundamentados na dignidade humana, servindo de base para a teoria de Alexy. Para o professor Freitas, "direitos fundamentais são posições, situações ou condições de vantagem jurídica material e formalmente supra ordenadas que tanto fundamentam direitos subjetivos deferindo imunidades à autodeterminação individual (desejos) e fundamentando expectativas de satisfação de necessidades humanas quanto compõe objetivamente o ordenamento jurídico condicionado materialmente a validade das normas jurídicas, atos 
significa, portanto, aqueles direitos inscritos em uma Constituição específica, com valores próprios da comunidade à qual ela exerce a sua força e reflete os seus princípios e normas.

Em sendo a Constituição aquela que irradia sua superioridade de normas para todo o sistema jurídico, deve-se compreender que tal superioridade é também estendida às relações entre particulares, ou melhor, às relações de direitos fundamentais entre os particulares, uma vez que as normas "e o fato de que estas, por uma deliberada escolha do constituinte, versam também sobre as relações privadas, possibilitam que se conceba a Lei Maior como novo centro do Direito Privado"29. Portanto, a força normativa constitucional, ao irradiar-se em todo o ordenamento jurídico, está irradiando também no direito civil, o qual deve compreender os seus preceitos e aplicá-los nas práticas civilistas.

Com a Constituição Federal de 1988, os princípios normativos constitucionais quebram paradigmas, submetendo "o direito positivo privado aos fundamentos de validade constitucionalmente estabelecidos, ou seja, é fazer uma releitura do direito civil à luz dos princípios e regras constitucionais" ${ }^{\prime 3}$, interpretando o direito civil à luz da Constituição, ocorrendo, deste modo, uma reforma estrutural do diploma civil nesse sentido, como é bem perceptível a partir da reforma do Código Civil (Lei 10.406 de 2002).

Ou seja, as normas infraconstitucionais necessitavam ser moldadas ao novo paradigma dos preceitos constitucionais, provenientes dos direitos fundamentais, da dignidade da pessoa humana e da igualdade substancial. Nesse sentido, normas anteriores à Constituição que vinham de encontro à mesma estavam necessariamente revogadas. Já as regras posteriores que conflitassem eram tidas como inconstitucionais e sem efetividade no mundo jurídico, obedecendo à hermenêutica da hierarquia das leis ${ }^{31}$.

administrativos e atos jurisdicionais".

29 SARMENTO, Daniel. Direitos fundamentais e relações privadas. Rio de Janeiro: Lumen Juris, 2004.

30 REIS, Jorge Renato dos. A constitucionalização do direito civil privado e o novo Código Civil. In: LEAL, Rogério Gesta (Org.). Direitos sociais e políticas públicas: desafios contemporâneos. Tomo 3. Santa Cruz do Sul: EDUNISC, 2003. p. 787.

31 REIS, Jorge Renato dos. A constitucionalização do direito civil privado e o novo Código Civil. In: LEAL, Rogério Gesta (Org.). Direitos sociais e políticas públicas: desafios contemporâneos. Tomo 3. Santa Cruz do Sul: EDUNISC, 2003. 
A dignidade da pessoa humana é erigida pela Constituição Federal de 1988 como fundamento da República, colocando a pessoa no centro do sistema jurídico. As normas constitucionais ${ }^{32}$ conferem unidade sistemática a todo o ordenamento jurídico. O direito passa a ter como fim primordial a proteção da pessoa humana, que é percebida como instrumento para seu pleno desenvolvimento. ${ }^{33}$

O atual constitucionalismo consubstancia-se em uma ordem de princípios e valores, pois o constituinte, ao definir "os objetivos fundamentais do Estado, [...] orientou a compreensão e interpretação do ordenamento constitucional pelo critério do sistema de direitos fundamentais" ${ }^{\prime 34}$. Há uma quebra do pensamento privatista e individualista.

[...] as relações jurídicas de Direito Privado devem ser interpretadas à luz da Constituição, seja em obediência às escolhas político-jurídicas do constituinte, seja em favor da proteção da dignidade, princípio capaz de conformar um novo conceito de ordem pública, fundado na solidariedade social e na plena realização da pessoa humana ${ }^{35}$.

Vive-se um pós-positivismo que se amolda ao legalismo com seu conjunto de ideias difusas que ultrapassam o legalismo estrito do positivismo normativista. Acendem-se os valores, a normatividade dos princípios e a essencialidade dos direitos fundamentais, bem como retoma uma discussão ética ao direito nesse momento. Componentes teóricos são reelaborados: pluralismo político e jurídico, nova hermenêutica e ponderação de interesses ${ }^{36}$. E a solidariedade não só como princípio, mas como direito fundamental faz parte desse contexto.

32 Uma vez que a Constituição é percebida como um sistema aberto, princípios e regras são diferenciados. O princípio apresenta uma carga valorativa, fundamento ético, uma decisão política relevante, determinando uma direção a ser seguida, enquanto a regra pode ser conceituada como um mandado de definição, ou seja, o famoso tudo ou nada (BARROSO, 2003).

33 FACHIN, Luiz Edson. Apreciação crítica do Código Civil de 2002 na perspectiva Constitucional do Direito Civil Contemporâneo. Revista Jurídica. No 34. São Paulo: Notadez Informação Ltda. Fevereiro/2003.

34 CITTADINO, Gisele. Judicialização da política, constitucionalismo democrático e separação de poderes. In: VIANA, Luiz Werneck (Org.). A democracia e os três poderes no Brasil. Belo Horizonte: IUPERJ/FAPERJ, 2002. p. 26.

35 TEPEDINO, Gustavo. Normas Constitucionais de Direito Civil na construção unitária do ordenamento. CONRADO, M.; PINHEIRO, R. F. Direito Privado e Constituição: ensaios para uma recomposição valorativa da pessoa e do patrimônio. Curitiba: Juruá, 2009. p. 45.

36 BARROSO, Luís Roberto (Org.). A nova interpretação constitucional. Ponderação, direitos fundamentais e relações privadas. Rio de Janeiro: Renovar, 2003. 
Onovodireitoconstitucionalbrasileirocoincidecomoprocessoderedemocratização, preocupando-se com a efetividade das normas constitucionais (força normativa da Constituição), dogmática da interpretação constitucional embasada em novos métodos hermenêuticos e na sistematização de princípios específicos de interpretação constitucional. A Constituição é o centro do sistema jurídico, apresentando função de filtragem constitucional do sistema infraconstitucional ${ }^{37}$. O Código Civil, que sempre serviu como a lei maior para a regulação das relações entre particulares, sofre a incidência dos valores constitucionais ${ }^{38}$.

Ante o texto constitucional, resta evidente a busca do equilíbrio entre a esfera de proteção social e o regime capitalista de mercado. O Estado assume o papel de médium entre sua função de regulador econômico em contraponto ao seu papel de garantidor social, perquirindo sempre a proteção da dignidade da pessoa humana e concretização dos direitos fundamentais.

Assim, os direitos patrimoniais, as liberdades econômicas e a autonomia privada são protegidos pelo próprio sistema que se diz aberto (regras e princípios norteadores) em favor da dignidade humana. A partir dessa lógica de freios e contrapesos da atuação estatal, a autonomia privada nas relações entre particulares e entre esses e o Estado é vislumbrada como fundamento constitucional do Estado sendo respeitado sob o viés da dignidade da pessoa humana ${ }^{39}$.

Há uma releitura dos institutos do direito civil amparada nos preceitos da Constituição Federal ${ }^{40}$. A norma continua sendo de direito privado, entretanto é

37 BARROSO, Luís Roberto (Org. ). A nova interpretação constitucional. Ponderação, direitos fundamentais e relações privadas. Rio de Janeiro: Renovar, 2003.

38 "[...] A leitura do direito civil sob a ótica constitucional atribui novos fundamentos e, conseqüentemente, novos contornos à liberdade contratual. Em meio ao processo de despatrimonialização ou de funcionalização do direito civil, a noção de autonomia da vontade sofre profundas modificações no âmbito do contrato, sintetizadas na afirmação de que a autonomia negocial, diferentemente das liberdades existenciais, não constitui em si mesma um valor. Ao contrário, a livre determinação do conteúdo do regulamento contratual encontra-se condicionada à observação das regras e dos princípios constitucionais, o que significa, no quadro de valores apresentado pela Constituição brasileira, conceber o contrato como um instrumento a serviço da pessoa sua dignidade e seu desenvolvimento. Assim, pela via da constitucionalização, passam a fazer parte do horizonte contratual noções e ideais como justiça social, solidariedade e erradicação da pobreza [...]" (NEGREIROS, 2006, p.106-107).

39 SARMENTO, Daniel. Direitos fundamentais e relações privadas. Rio de Janeiro: Lumen Juris, 2004.

40 Foi-se o tempo em que as relações privadas tinham presente em sua essência a ideia individualista, em que propriedade, contratos e família eram institutos cujas bases esta- 
irradiada pela hermenêutica constitucional. A constitucionalização do direito civil é uma realidade do ordenamento jurídico.

\section{A (IN)EFICÁCIA DOS DIREITOS FUNDAMENTAIS NO DIREITO CIVIL}

Com a Constituição Federal de 1988, os direitos fundamentais representam a positivação constitucional de valores básicos, responsáveis pelo resguardo da dignidade da pessoa humana, seja sob um aspecto individual, social ou até mesmo a partir da perspectiva de novos direitos.

O sistema jurídico contemporâneo brasileiro traz elencado em sua Constituição um rol de direitos fundamentais e, ainda, o princípio da dignidade humana, norteador de todo ordenamento jurídico. Tal princípio, inerente a todos os seres humanos, independente de merecimento pessoal ou social. Assim, como direito positivado, a dignidade da pessoa humana assume status de "super princípio", com conteúdo jurídico capaz de associá-la aos direitos fundamentais, com o fim de proporcionar um norte axiológico ao ordenamento jurídico, proporcionando assim uma coerência valorativa ${ }^{41}$.

Ainda como características do atual constitucionalismo contemporâneo emergem os direitos fundamentais em conjunto com a jurisdição constitucional, com o fim primordial de organizar a sociedade a partir da garantia de direitos. Com a evolução dos direitos fundamentais, é superada a ideia de que tais direitos possuem dimensão meramente axiológica, passando à posição de norma jurídica. A partir da evolução dos direitos fundamentais, estes passam a ser agregados como gerações ou dimensões ${ }^{42}$, donde novos direitos surgem, fruto

vam arraigadas por princípios eminentemente privados, sem qualquer ingerência estatal. O processo de constitucionalização do direito privado modifica totalmente esse contexto, uma vez que os princípios compõem todas as relações, seja de ordem pública ou privada (TERRA; PELLEGRINI, 2013, p. 68).

41 REIS, Jorge Renato dos. Os direitos fundamentais de tutela da pessoa humana nas relações entre particulares. In: REIS, Jorge Renato dos; LEAL, Rogério Gesta (Orgs.). Direitos sociais e políticas públicas: desafios contemporâneos. Tomo 7. Santa Cruz do Sul: EDUNISC, 2007.

42 Sarlet (2003) esclarece a atualidade das dimensões dos direitos fundamentais caracterizando a $1^{\text {a }}$ dimensão como sendo de cunho individualista, destacando-se na representação de direitos de defesa para a autonomia individual, arraigados pelo pensamento liberalburguês, cuja caracterização primordial se atém ao comportamento negativo por parte do 
de um processo dinâmico de conquistas da sociedade ou, ainda, da evolução da natureza humana ${ }^{43}$.

Para Sarlet (2003), há uma preocupação com a fundamentalidade formal e material dos direitos fundamentais na Constituição Federal de 1988, encontrandose a mesma ligada ao direito constitucional positivo, uma vez que: a) os direitos fundamentais situam-se no ápice de todo o ordenamento jurídico; b) na qualidade de normas constitucionais, encontram-se submetidos aos limites formais (procedimento agravado) e aos materiais (cláusulas pétreas) da reforma constitucional, conforme art. 60 da CF; e c) como normas diretamente aplicáveis, que se vinculam de forma imediata às entidades públicas e privadas, como se verifica no art. $5^{\circ}, \S 1^{\circ}, \mathrm{CF}$.

Nesse diapasão, a posição hierarquicamente superior dos direitos fundamentais é amplamente vislumbrada, pois resta evidente uma fundamentalidade reconhecida frente à universalidade das normas jurídicas. Entretanto, se os direitos fundamentais carregam consigo valores do Estado Democrático de Direito, que por sua vez devem permear todo o ordenamento, deve-se pensar nesse momento como isso acontece ante a seara do direito civil, eis que os direitos fundamentais

Estado (direito de liberdade, vida, propriedade, igualdade). Na 20 dimensão, são trazidos os direitos econômicos, sociais e culturais, e o Estado passa a ter um comportamento mais ativo, uma vez que os direitos passam a ter um cunho mais positivo, percebidos como liberdades sociais. O momento histórico que esses direitos passam a ser reconhecidos está identificado como sendo de grandes problemas sociais e econômicos, industrialização e doutrinas socialistas em voga, buscando-se de certo modo a justiça social (direito à assistência social, saúde, educação, trabalho). Na 3a dimensão há o desprendimento do individualismo, e a titularidade dos direitos se dão de forma coletiva e difusa. Interessante também situar o momento histórico, qual seja, pós Segunda Guerra Mundial, caracterizado pelo alto impacto tecnológico. Fala-se em direitos de solidariedade e fraternidade nessa dimensão, cujo destinatário é o "gênero humano", como bem relembra Bonavides. Pérez Luño diz ser essa dimensão uma "resposta à poluição das liberdades", causada pela "erosão e degradação dos direitos fundamentais" (direito à paz, autodeterminação dos povos, desenvolvimento, meio ambiente, qualidade de vida, comunicação). Já a $4^{a}$ e a $5^{a}$ dimensões não são tão desenvolvidas doutrinariamente pelo autor, uma vez que este se atém a mencionar posicionamentos de outros autores, considerando, portanto, tais dimensões prolongamentos daquelas já existentes. Assim, destaque merece Paulo Bonavides, quando aduz que os direitos fundamentais de $4^{a}$ geração são resultantes da globalização dos direitos fundamentais (direito à democracia direta, informação, pluralismo, biotecnologia). Ou, ainda, José Alcebíades de Oliveira Júnior, que considera a existência de uma $5^{a}$ dimensão.

43 REIS, Jorge Renato dos. Os direitos fundamentais de tutela da pessoa humana nas relações entre particulares. In: REIS, Jorge Renato dos; LEAL, Rogério Gesta (Orgs.). Direitos sociais e políticas públicas: desafios contemporâneos. Tomo 7. Santa Cruz do Sul: EDUNISC, 2007. 
também serão vinculados, saindo, portanto, do plano vertical para se contemplar também em um plano horizontal.

A eficácia irradiante dos direitos fundamentais manifesta-se sobretudo em relação à interpretação e aplicação das cláusulas gerais e conceitos jurídicos indeterminados, presentes na legislação infraconstitucional. Conceitos como boa-fé, ordem pública, interesse público, abuso de direito, bons costumes, dentre tantos outros, abrem-se, pela sua plasticidade, a uma verdadeira reconstrução, edificada à luz dos direitos fundamentais ${ }^{44}$.

Sarlet ${ }^{45}$, quando analisa o duplo caráter dos direitos fundamentais, quais sejam: formal e material ${ }^{46}$, e sua conexão com os seus destinatários, apresenta a "eficácia vertical" na seara privada, uma vez que há a vinculação de entidades estatais públicas a particulares (relações particular x Estado) e, por outro lado, a "eficácia horizontal"47, que trata da eficácia ${ }^{48}$ dos direitos fundamentais entre

44 SARMENTO, Daniel. Direitos fundamentais e relações privadas. Rio de Janeiro: Lumen Juris, 2004. p. 158.

45 SARLET, Ingo Wolfgang. Direitos Fundamentais e Direito Privado: algumas considerações em torno da vinculação dos particulares aos direitos fundamentais. In: SARLET, Ingo Wolfgang (Org.). A Constituição concretizada: construindo pontes com o público e o privado. Porto Alegre: Livraria do Advogado, 2000.

46 O conceito materialmente aberto de direitos fundamentais no direito constitucional é traduzido pelo art. 50, § 20, CF, uma vez que existem direitos que, por seu conteúdo e substância pertencem, mesmo que não estando positivados, ao catálogo de direitos fundamentais de um Estado, estando implicitamente e indiretamente incluídos, mesmo que não expressamente previstos. Neste sentido, há uma grande discussão doutrinária. Ainda, cumpre ressaltar o princípio da dignidade da pessoa humana, cujo conceito apresenta-se materialmente aberto, devendo servir de luz para a interpretação dos direitos fundamentais. Também há de se sobressaltar a existência de direitos fundamentais fora do catálogo, mas com status constitucional formal, bem como os direitos fundamentais sediados em tratados internacionais, destacando que a CF/88 aderiu à tendência do constitucionalismo contemporâneo, dispensando o tratamento privilegiado dos direitos humanos, uma vez que se entende que o ser humano detém uma posição central frente ao sistema. Também ressaltado ainda pelo autor direitos fundamentais que, em virtude da sua forma de positivação, assumem a aparência de normas organizacionais, como no caso (alistamento eleitoral, inelegibilidade) (SARLET, 2003).

47 É interessante quando Sarlet chama a atenção para a questão histórica do Estado para a efetiva compreensão da eficácia horizontal, uma vez que a transição do Estado Liberal de Direito (o qual detinha o dever de proteção às liberdades dos indivíduos contra interferências dos entes públicos) para o Estado Social de Direito (em que são ampliadas as funções estatais e a sociedade participa muito mais no exercício do poder) será observada a partir do modo de proteção dos direitos constitucionalmente garantidos aos indivíduos, dando-se não mais somente contra o próprio Estado, mas sim também contra outros detentores de poder na esfera privada (SARLET, 2000).

48 Pereira (2006) explica que a "Teoria da Eficácia Vertical dos Direitos Fundamentais" diz respeito à aplicabilidade dos direitos fundamentais como limitadores da atuação do Estado em uma relação vertical entre Estado e indivíduo como forma de proteção das liberdades individuais (ou os direitos de primeira dimensão), impedindo a interferência estatal na vida 
particulares, ou seja, da vinculação de pessoas físicas ou jurídicas aos direitos fundamentais. $\mathrm{O}$ autor vislumbra como os particulares podem se apropriar da perspectiva dos direitos fundamentais ante as relações privadas, uma vez que é viabilizado um direito fundamental contra outro particular que também detém seu direito fundamental.

Os direitos fundamentais são para todos, logo é possível, a partir de uma hermenêutica constitucional, trazer suas perspectivas às relações entre particulares. Steinmetz ${ }^{49}$ denota que a eficácia dos direitos fundamentais nas relações privadas vai encontrar seu respaldo inicialmente no princípio da supremacia da Constituição, eis que esta vincula todos seus entes, seja de forma direta ou indireta. Ademais, o autor ainda reforça o raciocínio da unidade material do ordenamento jurídico, trazendo os direitos fundamentais como núcleo material da Constituição, unificando, portanto, o ordenamento.

A "eficácia irradiante dos direitos fundamentais"50 reforça a ideia de que estes devem ter alcance em todo o ordenamento jurídico, inclusive no de ordem privada, pois se tratam de princípios constitucionais de uma ordem jurídica una.

Nesse sentido, o autor traz à tona a questão da "eficácia direta ou imediata" dos direitos fundamentais, que vincula diretamente o fato gerado entre particulares à Constituição, já que os valores constantes dela se irradiam por todo ordenamento jurídico, não podendo o Direito Privado ficar à margem dessa interpretação. Os direitos fundamentais não carecem de qualquer espécie de transformação para que sejam aplicados nas relações jurídico-privadas, restando proibido qualquer limitação a esses direitos.

Já com relação à "eficácia indireta ou mediata", a eficácia irradiante dos direitos fundamentais passa por uma "reconstrução", termo utilizado pelo autor, que significa

privada - ou direitos de defesa do indivíduo perante o Estado. Já a "Teoria da Eficácia Horizontal dos Direitos Fundamentais" prevê o Estado como guardião dos direitos fundamentais, tendo os particulares como destinatários dos preceitos constitucionais.

49 STEINMETZ, Wilson. A vinculação dos particulares a direitos fundamentais. São Paulo: Malheiros, 2004.

50 SARLET, Ingo Wolfgang. Direitos Fundamentais e Direito Privado: algumas considerações em torno da vinculação dos particulares aos direitos fundamentais. In: SARLET, Ingo Wolfgang (Org.). A Constituição concretizada: construindo pontes com o público e o privado. Porto Alegre: Livraria do Advogado, 2000. 
que ela somente ocorreria na ausência de normas jurídico-privadas, procedendo-se a uma interpretação e integração das chamadas "cláusulas gerais" do direito privado, tendo por horizonte os direitos fundamentais. Aqui há de se ressaltar que ocorre a recepção dos direitos fundamentais pelo Direito Privado, não sendo estes diretamente oponíveis entre particulares, uma vez que necessitam de uma transposição por meio de uma interpretação conforme os direitos fundamentais ${ }^{51}$.

Para Sarlet ${ }^{52}$, fica bem claro que os particulares estão diretamente vinculados pelas normas definidoras de direitos fundamentais, bem como os órgãos estatais, em especial o legislador e os órgãos jurisdicionais, uma vez que os direitos fundamentais são ferramentas de composição de conflitos e tensões. Resta claro que ante o conflito entre autonomia privada e direitos fundamentais caberá sempre a análise concreta do caso a partir da ponderação entre os direitos fundamentais em conflito.

A vinculação dos direitos fundamentais às relações privadas não significa que tal vinculação deva ocorrer em conformidade absoluta com os direitos fundamentais ${ }^{53}$, uma vez que existem situações em que tais direitos serão conflitantes, em que uns deverão ser protegidos em detrimento de outros para preservação das relações sociais. Porém, ante a inevitável evolução da humanidade, faz-se necessário que o direito, em especial o direito privado, ajuste-se a este processo evolutivo, tendo como princípio norteador a dignidade da pessoa humana ${ }^{54}$.

51 REIS (2005, p. 1502) esclarece as teorias de afirmação de existência de vinculação dos particulares aos direitos fundamentais dizendo que, enquanto alguns doutrinadores defendem a vinculação indireta (medita), outros remetem à tese da vinculação direta (imediata). Para a primeira corrente, explica o autor "há necessidade de existência de um processo de transmutação, caracterizado pela aplicação, interpretação e integração das cláusulas gerais e conceitos indeterminados do direito privado com preenchimento valorativo à luz dos direitos fundamentais". Já a segunda corrente defende que "em razão de os direitos fundamentais constituírem normas de valor válidas para toda a ordem jurídica, e em razão, da força normativa da Constituição, não é possível ao direito privado estar isento desse sistema, excluído da ordem constitucional".

52 SARLET, Ingo Wolfgang. Direitos Fundamentais e Direito Privado: algumas considerações em torno da vinculação dos particulares aos direitos fundamentais. In: SARLET, Ingo Wolfgang (Org.). A Constituição concretizada: construindo pontes com o público e o privado. Porto Alegre: Livraria do Advogado, 2000.

53 Cabe salientar que o catálogo de direitos fundamentais não fica restrito ao rol de direitos constitucionalizados, uma vez que estes direitos apresentam uma "textura aberta", o que proporciona a incorporação, pela constituição, de direitos formais (constantes do catálogo de direitos) e direitos materiais (equiparados a direitos fundamentais formais em razão de sua importância para a proteção da pessoa humana) (REIS, 2007).

54 REIS, Jorge Renato dos. Os direitos fundamentais de tutela da pessoa humana nas rela- 
Com a evolução das relações sociais, essa concepção dos direitos fundamentais alterou-se, dando nova forma ao direito privado. Assim a questão encontra-se em se e como os direitos fundamentais podem ser empregados como critérios normativos na solução de problemas envolvendo potenciais lesões a direitos fundamentais na esfera privada ${ }^{55}$.

Nesse sentido, a solidariedade, objeto do próximo item, aparece como um instrumento do direito civil, que incide diretamente nas relações entre particulares, de modo a viabilizar a sua aplicação como direito fundamental.

\section{A SOLIDARIEDADE E OS INSTRUMENTOS DE DIREITO CIVIL: A APLICAÇÃO DO DIREITO FUNDAMENTAL À SOLIDARIEDADE}

O direito de solidariedade ${ }^{56}$ apresenta função simbólica e uma nova capacidade de ação da sociedade. Desde já imprescindível esclarecer que a solidariedade aqui tratada em momento algum estará conectada ao sentido de "caridade" ou "filantropia", mas sim ao contexto de um direito fundamental como um veículo condutor da efetivação dos direitos fundamentais, raciocínio que será posteriormente desenvolvido para a compreensão de tal perspectiva.

Para Perlingieri ${ }^{57}$, a solidariedade assim como a igualdade são princípios são instrumentos que servem para potencializar a atuação da dignidade da pessoa humana no sentido de ser concretizador do princípio da dignidade da pessoa

ções entre particulares. In: REIS, Jorge Renato dos; LEAL, Rogério Gesta (Orgs.). Direitos sociais e políticas públicas: desafios contemporâneos. Tomo 7. Santa Cruz do Sul: EDUNISC, 2007.

55 PEREIRA, Jane Reis Gonçalves. Apontamentos sobre a Aplicação das Normas de Direito Fundamental nas Relações Jurídicas entre Particulares. In: BARROSO, Luís Roberto (Org.)

A Nova Interpretação Constitucional: Ponderação, Direitos Fundamentais e Relações Privadas. Rio de Janeiro: Renovar, 2006.

56 Para Warat (2004, p. 388): "A solidariedade é uma forma fundamental de reclamo. Ela nos coloca diante do conteúdo mais nobre do nosso compromisso com os socialmente excluídos e existencialmente desaparecidos. A solidariedade representa um estar junto dos oprimidos, participando comprometidamente em suas lutas transgressoras [...]. Quando se pratica a solidariedade, está-se reconhecendo a existência do outro como diferente, está aceitando-o sem pretender narcisisticamente fusioná-lo com o modelo de homem que o imaginário instituído produz como fantasia tanática".

57 Perlingieri, Pietro. Perfis do Direito Civil. Trad. Maria Cristina de Cicco. 2 ed. Rio de Janeiro: Renovar, 2002. 
humana ante as relações entre particulares ${ }^{58}$.

Há que se asseverar que o princípio em questão não produz resultados isoladamente, uma vez que possui alguns "aliados" que servem de base, como a igualdade formal e material, o personalismo e a fraternidade. Desta forma, os princípios da solidariedade e da igualdade apresentam-se como resultados e instrumentos, de forma a proporcionar a atuação da dignidade da pessoa humana em seu meio ${ }^{59}$.

Entretanto, imprescindível trazer de forma genérica que o discurso da solidariedade foi sistematizado conceitualmente por Léon Bourgeois e Durkheim, sendo posteriormente retomado por Léon Duguit, Maurice Hauriou Georges Gurvitch. A preocupação dos autores consistiu justamente em redefinir o papel do Estado e do Direito. Duguit retoma a ideia de solidariedade como norma de direito objetivo. Já Maurice Hauriou atrela seu sentido de solidariedade por meio da "instituição" como "organismo-representativo". Georges Gurvitch direcionase a partir dos referenciais teóricos anteriores à "ideia do direito social". No Brasil do final do século XIX e início do século XX, o discurso solidarista é vislumbrado em autores como Rui Barbosa, Tobias Barreto e Joaquim Nabuco ${ }^{60}$.

O surgimento do discurso solidarista está associado à crise do modelo liberal a partir das transformações econômicas e sociais da metade do século XIX, quando o movimento operário protagoniza multiplicidades e ambiguidades. Nesse momento o discurso solidarista representa uma crítica à democracia burguesa, servindo como agente de reconhecimento e ampliação do sufrágio universal, das liberdades políticas, dos direitos sociais e da democracia representativa, assumindo, portanto, uma nova forma de se pensar o direito, a sociedade e o próprio Estado. Portanto, o direito de solidariedade é situado num espaço 58 Solidariedade e igualdade agindo conjuntamente permitem um nivelamento das relações sociais, onde a igualdade é considerada enquanto fonte de legitimação de restrições a outros direitos, uma vez que estabelece o gozo racional dos direitos. Já a solidariedade, ligada a igualdade, visa uma harmonia das relações sociais, na medida em que permite a ponderação e o aperfeiçoamento da liberdade e da igualdade (REIS, 2007).

59 REIS, Jorge Renato dos. Os direitos fundamentais de tutela da pessoa humana nas relações entre particulares. In: REIS, Jorge Renato dos; LEAL, Rogério Gesta (orgs.). Direitos sociais e políticas públicas: desafios contemporâneos. Tomo 7. Santa Cruz do Sul: EDUNISC, 2007.

60 FARIAS, José Fernando de Castro. A origem do direito de solidariedade. Rio de Janeiro: Renovar, 1998. 
complexo que repudia o exacerbado formalismo jurídico e toda a visão monista do direito e do poder, intimamente ligado à prática pluralista proveniente de toda a sociedade. As decisões político-jurídicas são frutos da sociedade complexa ${ }^{61}$ junto com o Estado e o direito. O pluralismo jurídico é visualizado como uma consequencia direta de uma nova solidariedade social e alto grau de complexidade da sociedade contemporânea ${ }^{62}$.

A esfera pública se torna referência de um mundo em comum cuja formação da identidade preocupa-se também com o outro, uma vez que ocorre o efetivo reconhecimento da pluralidade e da heterogeneidade. Deste modo, evidente que não se pode falar em solidariedade sem o respeito à liberdade e vice-versa. O discurso solidarista nasce da descoberta da solidariedade e do confronto das ideias do solidarismo de Proudhon, da perspectiva revolucionária (marxismo, anarquismo, sindicalismo revolucionário), do projeto social-democrata, da tendência reformista e do solidarismo sociológico de L. Bourgeois, A. Fouillé e, principalmente, Durkheim. Das ideias solidaristas a sociedade passa a ser imaginada por meio de uma solidariedade flexível, pluralista e global, que equilibra a socialização e a individualização. Há uma visão orgânica da sociedade pela flexibilidade dos mecanismos de regulação social, acompanhando o homem em todo o processo de socialização ante a incorporação dos movimentos sociais à racionalidade jurídica ${ }^{63}$.

Ainda, não se pode negar a ligação da solidariedade à democracia, destacando ser essa a subordinação das instituições à liberdade individual e coletiva, preocupada com a proteção da liberdade contra o poder político-econômico e contra a pressão da comunidade, trazendo, nesse sentido, constantemente, uma transformação de simples sujeitos para sujeitos conscientes de suas liberdades e

61 Para Reis e Fontana (2010, p. 3340), a efetivação dos direitos sociais pressupõe uma nova maneira de pensar a ciência jurídica, uma vez que o atual modelo de Constituição "contempla um processo democrático de valorização das questões sociais, enquanto a real efetivação encontra-se paralisada [...]. A solidariedade, utilizada como sustentáculo dos direitos sociais, é valor hermenêutico, e, apoiada na proibição do retrocesso social, concentra a ideia de força pela construção de uma interpretação mais ativa, que envolva a consciência do homem enquanto ser coletivo".

62 FARIAS, José Fernando de Castro. A origem do direito de solidariedade. Rio de Janeiro: Renovar, 1998.

63 FARIAS, José Fernando de Castro. A origem do direito de solidariedade. Rio de Janeiro: Renovar, 1998. 
de suas responsabilidades frente a si mesmos e aos outros ${ }^{64}$.

O conceito de solidariedade é muito amplo. Entretanto, para facilitar o entendimento, pode-se dividi-lo sob alguns enfoques, quais sejam: valor moral, valor ético e valor jurídico. Sob o aspecto moral, a solidariedade é entendida como generosidade, bondade e compaixão, intimamente ligada à ideia de caridade proveniente do cristianismo ${ }^{65}$. Na perspectiva ética, o sentido encontrase conectado à solidariedade filosófica, ou seja, a partir da cooperação com o outro, como dever se responsabilidade para com o outro sob uma perspectiva de alteridade ${ }^{66}$. Já como valor jurídico-social, pretende reunir as pessoas sob uma perspectiva do bem comum, dizendo respeito a todas as partes de um todo social. No presente artigo, foca-se a solidariedade como um valor.

O princípio da solidariedade orienta o direito num sentido propriamente de valor, revelando que o reconhecimento da dignidade humana é uma forma de preservação da vida e da liberdade com igualdade e que, preceitos como justiça, ética e valor da pessoa humana constituem a base fundamental para que o direito seja efetivamente um fator de transformação social. A solidariedade visa a um direito ético e justo, direcionado para o bem comum, assim, afirma-se como um novo paradigma cuja sociedade civil interage para a evolução da humanidade e o direito por sua vez capacita-se para regular as ações individuais em benefício de um social difuso ${ }^{67}$.

Reis e Fontana (2011, p. 118) esclarecem que a solidariedade surge:

[...] de uma não normatividade, mas, sobretudo, de ações que movimentam e transformam a sociedade, por meio de práticas interventivas dos conflitos sociais. Teve sua noção de assistência mútua alicerçada no século XIX, quando passou a designar uma nova maneira de pensar a relação indivíduo-sociedade, todavia não se confunde com caridade, já que o objetivo é pensar a solidariedade como veículo

64 FARIAS, José Fernando de Castro. A origem do direito de solidariedade. Rio de Janeiro: Renovar, 1998.

65 CARDOSO, Alenilton da Silva. Princípio da Solidariedade: o paradigma ético do direito contemporâneo. São Paulo: Editora Juarez de Oliveira, 2010.

66 PERLINGIERI, Pietro. O direito civil na legalidade constitucional. Trad. Maria Cristina De Cicco. Rio de Janeiro: Renovar, 2008.

67 CARDOSO, Alenilton da Silva. Princípio da Solidariedade: o paradigma ético do direito contemporâneo. São Paulo: Editora Juarez de Oliveira, 2010. 
condutor de direitos sociais. É por meio de uma democracia realizada solidariamente que a sociedade se encontra na sua missão social.

A dignidade da pessoa humana é o epicentro do projeto solidarista e refletese em todo o ordenamento jurídico, sendo um novo paradigma ético na busca do bem comum, aparecendo como uma possível solução frente uma sociedade desigual e injusta, reconhecendo, nesse sentido, os direitos fundamentais, a dignidade da pessoa humana, os preceitos de justiça social e distributiva, bem como a funcionalidade dos institutos do Direito Privado ${ }^{68}$.

A sociedade de risco que atualmente está-se inserido tem que pelo menos possibilitar uma abertura do pensamento de modo a viabilizar a compreensão do que é pertencer em um Estado Democrático de Direito. Pensar novas formas e argumentos capazes de atender a efetiva dignidade da pessoa humana, a fim de que a vítima de um dano não reste sem ressarcimento, se faz necessário. Mas para tanto, indispensável a flexibilização do nexo de causalidade, pois teorias pragmáticas e fechadas de responsabilidade civil não atendem esse novo contexto de sociedade. Nesse contexto que a solidariedade deve ser percebida.

Situações que ilustram a viabilidade da utilização do direito fundamental à solidariedade podem auxiliar na compreensão e na dimensão que tem o instituto nos dias atuais. Cita-se, por exemplo, no Brasil a Lei $n^{\circ} 11.042$, de 18 de novembro de 1997, que reconheceu a responsabilidade do Estado do Rio Grande do Sul por danos físicos e psicológicos causados em pessoas que foram detidas por motivos políticos, estabelecendo indenizações. Ainda situações envolvendo vítimas de terrorismo também podem ser encaixadas na perspectiva de trazer a solidariedade como valor jurídico capaz de restabelecer a dignidade humana a partir de uma indenização. A lógica do sistema DPVAT, uma espécie de seguro social brasileiro, também é outro exemplo que pode ser trazido à baila, pois todos contribuem e quando ocorre um sinistro, o valor será disponibilizado para a cobertura de danos automobilísticos à vítima.

São algumas maneiras encontradas da aplicação da solidariedade na responsabilidade civil e o mais interessante é que para sua aplicação não há uma 68 CARDOSO, Alenilton da Silva. Princípio da Solidariedade: o paradigma ético do direito contemporâneo. São Paulo: Editora Juarez de Oliveira, 2010. 
necessidade de comprovação de culpa ou, ainda, a priorização da vítima do dano. Há uma relativização quanto ao nexo de causalidade de modo a visar à dignidade da pessoa humana, para que a vítima do dano não reste sem o devido ressarcimento.

Nem sempre a teoria da responsabilidade civil acompanhará os fatos da sociedade, para tanto, a perspectiva da solidariedade deve ser um fio condutor na construção do Estado Democrático de Direito.

Vive-se em uma época de fugaz velocidade, que muitas vezes assusta o ser humano, o qual é refém do ritmo frenético dos avanços constantes das tecnologias da informação e comunicação paralisa. O fenômeno da industrialização, as novas tecnologias, o avanço da ciência e as novas relações sociais podem ter um preço que até então não estava previsto na conta social, preço esse que pode ser pensado ante a solidariedade a partir de uma perspectiva da responsabilidade civil com a consequente reparação de vítimas nesses processos.

Portanto, com a percepção da solidariedade, evidencia-se uma nova realidade hermenêutica preocupada com uma sociedade livre, justa e solidária. Pode-se dizer que a própria Constituição Federal de 1988 é fruto de um movimento socializador e democrático e adota valores humanitários nas relações comunitárias para uma vida digna. Em seu art. $3^{\circ}$, I, é perceptível que as individualidades devem ser compatibilizadas com os interesses sociais da coletividade. Há, nesse sentido, uma maior preocupação com o "ser"69.

Um direito sob a ética solidarista ${ }^{70}$ não se coaduna com a ideologia individualista, sendo a atual Constituição Federal uma desafiante do sistema e da estrutura do direito, uma vez que se atém a finalidades sociais específicas: construção de uma sociedade livre e justa; garantia do desenvolvimento nacional; erradicação da pobreza e da marginalização, reduzindo as desigualdades sociais e regionais; promoção do bem-estar de todos, sem preconceitos de origem, raça, sexo, cor, 69 CARDOSO, Alenilton da Silva. Princípio da Solidariedade: o paradigma ético do direito contemporâneo. São Paulo: Editora Juarez de Oliveira, 2010.

70 Há uma nova visão do direito embasada nas linhas sociológicas e socialistas, as quais contribuíram consideravelmente para a construção da função social do direito e um novo olhar sobre a superação da distinção entre direito público e privado. A interseção jurídica entre o direito público e privado viabiliza, portanto, a construção sistemática do direito, possibilitando uma interpretação constitucional que ultrapassa os limites codicistas e foca para a concretude da justiça e dos princípios constitucionais (TERRA; PELLEGRINI, 2013). 
idade e qualquer outras formas de discriminação; uma ordem econômica fundada na valorização do trabalho humano e na livre iniciativa, cujo fim seja assegurar a todos uma existência digna, conforme os ditames da justiça social, nos termos do art. $3^{\circ}, 170, \mathrm{CF}^{71}$.

Assim, é possível afirmar que quando a Constituição estabelece como um dos objetivos fundamentais da República brasileira "construir uma sociedade justa, livre e solidária", ela não está apenas enunciando uma diretriz política desvestida de qualquer eficácia normativa. Pelo contrário, ela expressa um princípio jurídico, que, apesar de sua abertura e indeterminação semântica, é dotado de algum grau de eficácia imediata e que pode atuar, no mínimo, como vetor interpretativo da ordem jurídica como um todo ${ }^{72}$.

Denota-se ainda que também é atual a preocupação do direito privado com a realização dos interesses difusos e coletivos mediante os preceitos de justiça distributiva e social. É evidente a exigência da realidade social dos direitos subjetivos à compatibilização com os interesses sociais da humanidade, impulsionando comportamentos individuais em prol dos interesses sociais e difusos da comunidade ${ }^{73}$.

Portanto, a solidariedade como direito fundamental é possível ao passo que se encontra elencada no art. $3^{\circ}$, I, da Constituição Federal, sendo um princípio estruturante do Estado e, portanto, um dever fundamental de terceira dimensão, com status subjetivo e de aplicação às relações jurídicas de forma imediata, para inclusive particulares frente à responsabilidade civil, uma vez que a irradiação da Constituição expande-se para todo o direito.

A solidariedade não é uma imposição à liberdade individual, mas sim de um valor focado na dignidade da pessoa humana, que é atingido a partir da ponderação entre os valores da liberdade e da solidariedade, contrariando definitivamente a lógica da competição desmesurada de um capitalismo selvagem, perquirindo, portanto, a cooperação, a responsabilidade social, a igualdade substancial e a 71 CARDOSO, Alenilton da Silva. Princípio da Solidariedade: o paradigma ético do direito contemporâneo. São Paulo: Editora Juarez de Oliveira, 2010.

72 SARMENTO, Daniel. Direitos fundamentais e relações privadas. Rio de Janeiro: Lumen Juris, 2004. p. 295.

73 CARDOSO, Alenilton da Silva. Princípio da Solidariedade: o paradigma ético do direito contemporâneo. São Paulo: Editora Juarez de Oliveira, 2010. 
justiça distributiva e social ${ }^{74}$.

Em função do fenômeno da constitucionalização ${ }^{75}$, o Direito Civil, que sempre foi vislumbrado como um direito extremamente patrimonialista, passa a ser visto sob o manto da dignidade da pessoa humana, a qual se preocupa e volta os seus olhos para um desenvolvimento sob um viés da Justiça Social. Há uma preocupação com a função social ante a defesa de todo e qualquer direito. Vive-se, portanto, o momento da despatrimonialização ou repersonalização do Direito Civil ${ }^{76}$ ante a irradiação dos princípios e dos ideais trazidos pela Constituição Federal de 1988.

Osentido de solidariedade visado pelolegislador constituinte encontra-se no plano jurídico, destinando-se às relações interprivadas, em face da dimensão dos conteúdos trazidos pelos princípios constitucionais, servindo a mesma como fundamento plus, que enfatiza ainda mais os direitos fundamentais dos particulares ${ }^{77}$.

A solidariedade como direito fundamental é um atual paradigma das relações jurídicas, em especial entre particulares, e representa uma nova visão para o direito frente à iminente concretização da dignidade da pessoa humana.

\section{CONSIDERAÇÕES FINAIS}

De forma sucinta, a solidariedade pode ser percebida sob três perspectivas: a primeira como moral, a segunda como ética e a terceira como valor jurídico. $\mathrm{Na}$

74 CARDOSO, Alenilton da Silva. Princípio da Solidariedade: o paradigma ético do direito contemporâneo. São Paulo: Editora Juarez de Oliveira, 2010.

75 Para Maria Celina Bodin de Moraes, o Direito Civil Constitucionalizado é o Direito Civil transformado pela normativa constitucional, em que se verifica a superação da lógica patrimonial (proprietária, produtivista, empresarial) para a contemplação dos valores existenciais da pessoa humana, valores esses que devem ser absorvidos por todo o ordenamento jurídico e, portanto, agora prioritários no âmbito da regulação das relações entre particulares (MORAES, 1993).

76 Em relação à autonomia privada, de origem burguesa, atreladas à liberdade negocial, ampla e irrestrita, o que proporcionava uma série de injustiças, que acabavam encobertas pelo pacta sunt servanda. A autonomia privada acabou por sofrer limitações em razão da evolução dos direitos fundamentais, porém, na Constituição brasileira, é identificada pela leitura do texto constitucional, pelo qual recebe posição de direito fundamental, mesmo que não absoluto. Deve esta ser ponderada, observando-se o caso concreto, ainda, em virtude de outros princípios que protegem a dignidade humana, entre eles, a solidariedade e a igualdade (REIS, 2007).

77 REIS, Jorge Renato dos. Os direitos fundamentais de tutela da pessoa humana nas relações entre particulares. In: REIS, Jorge Renato dos; LEAL, Rogério Gesta (Orgs.). Direitos sociais e políticas públicas: desafios contemporâneos. Tomo 7. Santa Cruz do Sul: EDUNISC, 2007. 
perspectiva moral, a solidariedade é compreensível ante os princípios da confiança e da boa-fé. Já na perspectiva ética, o discurso se conectará à cooperação para com o outro. E, finalmente, a solidariedade como valor jurídico, que foi objeto do presente estudo. Nessa perspectiva, a solidariedade associa-se ao princípio de uma Justiça Social, perquirindo a ideia de responsabilidade para com o outro.

Nesse sentido, quando se trabalha a solidariedade como valor jurídico, isso implica percebê-la como um direito fundamental, uma vez que, para a sua compreensão de fato, é necessário um alargamento do nexo de causalidade, viabilizando o entendimento de responsabilidade a partir de tal fundamentação. Ou seja, constrói-se um argumento a partir das premissas já existentes na Constituição, fundamentadas principalmente na dignidade da pessoa humana e nos ideais trazidos pelo art. $3^{\circ}$, I, para contemplar as relações entre particulares.

Assim, pretendeu-se demonstrar a viabilidade do diálogo entre a solidariedade e a seara civil, tornando de forma imprescindível tal discurso para uma efetiva aplicação do instituto da solidariedade às relações privadas.

\section{REFERÊNCIAS}

ALEXY, Robert. Constitucionalismo discursivo. Tradução de Luís Afonso Heck. 2. ed. rev. Porto Alegre: Livraria do Advogado, 2008.

BARROSO, Luís Roberto.Fundamentos teóricos e filosóficos do novo direito constitucional brasileiro (pós-modernidade, teoria crítica e pós-positivismo). In: BARROSO, Luís Roberto (Org.). A nova interpretação constitucional. Ponderação, direitos fundamentais e relações privadas. Rio de Janeiro: Renovar, 2003.

BOBBIO, Norberto. A era dos direitos. Tradução de Carlos Nelson Coutinho. Apresentação de Celso Lafer. Nova Edição. 10 impressão. Rio de Janeiro: Elsevier, 2004.

CANOTILHO, José Joaquim Gomes. Direito Constitucional e a teoria da constituição. 2. ed. Coimbra: Almedina, 1998.

CARDOSO, Alenilton da Silva. Princípio da Solidariedade: o paradigma ético do direito contemporâneo. São Paulo: Editora Juarez de Oliveira, 2010.

CITTADINO, Gisele. Judicialização da política, constitucionalismo democrático e separação 
de poderes. In: VIANA, Luiz Werneck (Org.). A democracia e os três poderes no Brasil. Belo Horizonte: IUPERJ/FAPERJ, 2002.

DIMOULIS, Dimitri; MARTINS, Leonardo. Teoria geral dos direitos fundamentais. 3. ed. rev. atual. e ampl. São Paulo: Editora Revista dos Tribunais, 2011.

FACHIN, Luiz Edson. Apreciação crítica do Código Civil de 2002 na perspectiva Constitucional do Direito Civil Contemporâneo. Revista Jurídica. No 34. São Paulo: Notadez Informação Ltda. Fevereiro/2003.

FARIAS, José Fernando de Castro. A origem do direito de solidariedade. Rio de Janeiro: Renovar, 1998.

FREITAS, Luiz Fernando Calil de. Conceito, fundamento e significado dos direitos fundamentais. Palestra proferida no Curso de atualização em direitos fundamentais. 4. ed. Porto Alegre: Escola Superior de Advocacia, em 14 de outubro de 2013.

GORCZEVSKI, Clovis. Direitos humanos, educação e cidadania: conhecer, educar, praticar. Santa Cruz do Sul: Edunisc, 2009.

HAHN, Paulo. Repensar os Direitos Humanos no Horizonte da Pluralização e da Interculturalidade. In: HAHN, Paulo (Org.). Nova Petrópolis: Nova Harmonia, 2010.

LEAL, Rogério Gesta. Direitos Humanos no Brasil: desafios à democracia. Porto Alegre: Livraria do Advogado; Santa Cruz do Sul: Edunisc, 1997.

MORAES, Maria Celina Bodin. A caminho de um Direito Civil Constitucional. Revista de Direito Civil. São Paulo, v. 6, jul./set. 1993.

NEGREIROS, Teresa. Teoria do contrato, novos paradigmas. 2. ed. Rio de Janeiro: Renovar, 2006.

PEREIRA, Jane Reis Gonçalves. Apontamentos sobre a Aplicação das Normas de Direito Fundamental nas Relações Jurídicas entre Particulares. In: BARROSO, Luís Roberto (Org.) A Nova Interpretação Constitucional: Ponderação, Direitos Fundamentais e Relações Privadas. Rio de Janeiro: Renovar, 2006.

PÉREZ-LUÑO, Antonio Enrique. Derechos humanos, Estado de Derecho y Constitución. 9. ed. Madrid: Tecnos, 2005.

PERLINGIERI, Pietro. $\mathbf{O}$ direito civil na legalidade constitucional. Trad. Maria Cristina De Cicco. Rio de Janeiro: Renovar, 2008. 
. Perfis do Direito Civil. Trad. Maria Cristina de Cicco. 2. ed. Rio de Janeiro: Renovar, 2002.

REIS, Jorge Renato dos; FONTANA, Eliane. O princípio da solidariedade e a hermenêutica filosófica na sustentabilidade dos direitos fundamentais sociais, diante dos argumentos do mínimo existencial e da reserva do possível. In: Direitos sociais e políticas públicas: desafios contemporâneos. REIS, Jorge Renato dos; LEAL, Rogério Gesta (Orgs.). Tomo 10. Santa Cruz do Sul: EDUNISC, 2010.

. Os direitos fundamentais de tutela da pessoa humana nas relações entre particulares. In: REIS, Jorge Renato dos; LEAL, Rogério Gesta (Orgs.). Direitos sociais e políticas públicas: desafios contemporâneos. Tomo 7. Santa Cruz do Sul: EDUNISC, 2007.

A vinculação dos particulares aos direitos fundamentais nas relações interprivadas: breves considerações. In: Direitos sociais e políticas públicas: desafios contemporâneos. Tomo 5. Santa Cruz do Sul: EDUNISC, 2005.

A constitucionalização do direito civil privado e o novo Código Civil. In: LEAL, Rogério Gesta (Org.). Direitos sociais e políticas públicas: desafios contemporâneos. Tomo 3. Santa Cruz do Sul: EDUNISC, 2003.

SÁNCHEZ RUBIO, David. Fazendo e desfazendo direitos humanos. Tradução Clovis Gorczevski. Direito \& Sociedade Contemporânea. Vol. 9. 1. ed. Santa Cruz do Sul: Edunisc, 2010.

SARLET, Ingo Wolfgang. A eficácia dos direitos fundamentais: uma teoria geral dos direitos fundamentais na perspectiva constitucional. 10. ed. ver. atual. e ampl. Porto Alegre: Livraria do Advogado, 2009.

A eficácia dos direitos fundamentais. 3. ed. rev. atual e ampl. Porto Alegre: Livraria do Advogado, 2003.

. Direitos Fundamentais e Direito Privado: algumas considerações em torno da vinculação dos particulares aos direitos fundamentais. In: SARLET, Ingo Wolfgang (Org.). A Constituição concretizada: construindo pontes com o público e o privado. Porto Alegre: Livraria do Advogado, 2000.

SARMENTO, Daniel. Direitos fundamentais e relações privadas. Rio de Janeiro: Lumen Juris, 2004.

STEINMETZ, Wilson. A vinculação dos particulares a direitos fundamentais. São Paulo: Malheiros, 2004. 
STRECK, Lenio Luiz; MORAES, José Luis Bolzan de. Ciência Política e Teoria Gerald o Estado. 3. ed. Porto Alegre: Livraria do Advogado, 2003.

TEPEDINO, Gustavo. Normas Constitucionais de Direito Civil na construção unitária do ordenamento. CONRADO, M.; PINHEIRO, R. F. Direito Privado e Constituição: ensaios para uma recomposição valorativa da pessoa e do patrimônio. Curitiba: Juruá, 2009.

TERRA, Rosane B. M. da R. Barcellos; PELLEGRINI, Grace Kellen de Freitas. Inter-relações entre o direito público e o privado: uma abordagem do princípio da solidariedade nas relações privadas. In: Interseções jurídicas entre o público e o privado. REIS, Jorge Renato; CERQUEIRA, Kátia Leão. (Orgs.). Santa Cruz do Sul: Editora IPR, 2013.

WARAT, Luis Alberto. Epistemologia e ensino do direito: o sonho acabou. Vol. II. Florianópolis: Fundação Boiteux, 2004.

Recebido em: julho/2014 Aprovado em: set/2014 